opinion is always an option. Agreeing on which methods of life support are artificial and which natural is sometimes difficult, but if the doctors knew the patient's view of this borderline they might be protected rather than ensnared in law; they might thus be able to give more effective symptomatic relief and be more assured when making difficult decisions about altering plans for care.

Nobody could claim that living wills will ever be a real substitute for empathic communication between health workers, patients, and relatives. Certainly the best results are likely to arise from continuous care by a practitioner who "knew the patient's mind." Likewise, these documents will never cover all eventualities, and their legal status in Britain might take some time to become clear. Indeed, legislation should probably be avoided if the objectives of their use could be obtained without it. These and many other practical problems remain to be addressed. Careful studies by multidisciplinary groups are needed to weigh the evidence and identify possible strategies (Centre of Medical Law and Ethics, King's College, London, Living Wills Working Party, unpublished observations).

A living will may best be seen as an advisory device and need not become a legal weapon. But if our care is to anticipate and to prevent, it makes sense to know what the patient wanted. If there is doubt, where there is a will there may be a better way.

ROGER HIGGS

Director and Senior Lecturer,

Department of General Practice Studies,

King's College School of Medicine and Dentistry,

London SE5 8RX

1 Gillon R. Philosophical medical ethics. Chichester: Wiley, 1986.

2 Higgs R, Livesley B, Rennie J, and relatives. Earning his heroin but seeking release while the surgeon advises amputation. $\mathcal{f}$ Med Ethics 1987;13:43-8.

3 Higgs R. Kicking against the pricks: two patients wish to end essential insulin treatment. $\mathcal{F}$ Med Ethics 1984;10:201-8.

4 Kennedy IM. The Karen Quinlan case: problems and proposals. $\mathcal{f}$ Med Ethics 1976;2:3-7.

5 Tindall G. High-tech medicine: when to say no. $\mathcal{F} R$ Soc Med 1986;79:56-7.

6 Robinson GS. Dealing with the brain-damaged old-dignity before sanctity. $f$ Med Ethics 1982;8:173-9.

Health Advisory Service. The rising tide-developing services for mental illness in old age. London HAS, 1982.

8 Society for the Right to Die. Handbook of living will laws. New York: SRD, 1984

9 Rouse F. Living wills and the right to refuse treatment. Institute of Medical Ethics Bulletin 1987 April (suppl 5): 1-6, 23-4.

10 Department of Health and Social Security. Code of practice for the Mental Health Act (1983). London: DHSS, 1985.

11 Gray JAM. Section 47: an ethical dilemma for doctors. Health Trends 1980;3:72-4.

11 Gray JAM. Section 47: an ethical dilemma for doctors. Health Trends 1980;3:72-4.

12 Age Concern England. The law and vulnerable elderly people. Mitcham, Surrey: ACE, 1986. Lawrence University. Report from working group 1, intermational workin
decisions. Appleton, Winsconsin: Lawrence University, 1987.

14 Allen CMC. Predicting the outcome of acute stroke: a prognostic score. $f$ Neurol Neurosurg Psychiatry 1984;47:475-80.

15 Reisberg B. Dementia: a systematic approach to identifying reversible causes. Geriatrics 1986;41:30-46.

\section{Looking beyond oral rehydration therapy}

Oral rehydration therapy for diarrhoea is estimated to be saving the lives of half a million children every year, ${ }^{1}$ even though only two thirds of the population recognise its efficacy and only two fifths actually use it for treatment. ${ }^{2}$ Popularising the use of oral rehydration therapy is one of the strategies adopted by the United Nations Children's Fund in its child survival revolution, emphasising that it is simple, effective, and inexpensive. Meanwhile continuing research has proposed modifications in the original formula, with the promise that better clinical results may be obtained from "super oral rehydration therapy." ${ }^{3}$ Nevertheless, as in so many instances, a lasting impact on diarrhoeal disease will come about only through prevention rather than cure.

Several preventive programmes are being promoted with varying degrees of success in different countries. But each is being carried out independently and not as part of a concerted effort against diarrhoea. For example, breast feeding is one of the pillars of the United Nations Children's Fund child survival revolution, and it is also strongly recommended by the World Health Organisation. Its protective effects have been well documented-for example, a review of 35 studies from 14 countries. ${ }^{4}$

Another approach by the WHO is to promote actively its expanded programme of immunisation, which includes immunisation against measles. An attack of measles is sometimes followed by a severe and dysenteric form of diarrhoea often associated with shigella infection. Probably between 0.6 and $3.8 \%$ of diarrhoeal episodes and between 6 and $26 \%$ of the deaths from diarrhoea can be averted through measles immunisation. ${ }^{5}$ Moreover, new vaccines such as that against rotavirus ${ }^{6}$ and the improved cholera vaccine are expected to be added to the existing programme when they become available. The former would probably prevent $4 \%$ of the episodes and $13 \%$ of the deaths from diarrhoea; the benefits from the latter might be fewer, but in countries such as Bangladesh where cholera is endemic the vaccine will be immensely valuable.?

A third preventive programme is the International Water Supply and Sanitation Decade (1981-90), which aims at providing a good supply of drinking water and facilities for disposing of human waste. ${ }^{8} \mathrm{~A}$ review of 67 studies in 28 countries on the effects of improving the water supply has shown a median overall reduction in diarrhoeal morbidity of $22 \%$, which was as much as $27 \%$ in a few better designed projects. ${ }^{9}$ Improvements in personal and home hygiene resulting in the decreased faecal contamination of food and water are important. Education about washing the hands, for example, can reduce the secondary attack rates of diarrhoea within families by $85 \%$. Improved hygiene also has the added benefits of reducing diarrhoea caused by gut parasites such as Entamoeba histolytica, Giardia lambia, Staphylococcus stercoralis, Capillaria, and several others. Again it will help to interrupt the transmission of Shigella, which may cause epidemic outbreaks of diarrhoea. ${ }^{11}$

Thus all the ingredients for mounting a concerted effort at preventing childhood diarrhoea are there in varying degrees but they may not be benefiting most of the population. Many developing countries need not only preventive programmes, but also an adequate infrastructure for delivering primary health care. All developing countries are experiencing an unprecedented increase in the number of urban shanty towns, and with their unsanitary living conditions diarrhoea is bound to be a recurring and pernicious problem among the urban poor. Hence, firstly, an innovative approach to urban primary care is a priority. Secondly, any crash programmes of health education in the mass media must be coordinated with other activities in health so that the message is reinforced. The lack of such coordination was shown in the national campaigns for promoting breast feeding in Brazil and Malaysia: mothers attending the antenatal clinics were found to know about the advantages of breast feeding but were receiving no reinforcing education from health workers in the clinics. ${ }^{12}$ Given that most countries have a better infrastructure in education than in health, with primary schools in most settlements, school teachers and their pupils 
may be a more effective means of changing behaviour in traditional communities than the mass media.

Reader,

G J EBRAHIM

Tropical Child Health Unit,

Institute of Child Health,

London WCIN IEH

1 Grant JP. The state of the world's childen. 1987. Oxford: Oxford University Press, 1987:37.

2 World Health Organisation. Diarthoea disease control programme: fifth programme report. Geneva: WHO, 1986. (WHO/CDD/86.16.)

3 Patra FC, Mahalanabis D, Jalan KN, Sen A, Banerjee P. Is oral rice electrolyte solution superior to glucose electrolyte solution in infantile diarrhoea? Arch Dis Child 1982;57:910-2.

4 Feacham RG, Koblinsky MA. Interventions for the control of diarrhoeal diseases among young children: promotion of breast feeding. Bull WHO 1984;62:271-91.

5 Feacham RG, Koblinsky MA. Interventions for the control of diarrhoeal diseases among young children: measles immunization. Bull WHO 1983;61:641-52.

6 Flewett TH. Rotavirus vaccines-achievements and prospects. Arch Dis Child 1986;61:211-2.

7 de Zoysa I, Feacham RG. Interventions for the control of diarrhoeal diseases among young children: rotavirus and cholera immunization. Bull WHO 1985;63:569-83.

8 United Nations Children's Fund/World Health Organisation Joint Committee. Study on water supply and samitation components of primary health care. Geneva: World Health Organisation, supply and sanitation components of primary health care.

9 Essey SA, Feacham RG, Hughes JM. Interventions for the control of diarrhoeal diseases among young children: improving water supplies and excreta disposal facilities. Bull WHO 1985;63: 757-72.

10 Gangarosa EJ, Perera DR, Mata LJ, Mendizabal-Morris C, Guzman G, Reller L. Epidemic shigh bacillus dysentery in central America. II. Epidemiologic studies in 1969. I Infect Dis 1970;122: 181-90.

11 Khan MU. Interruption of shigellosis by hand-washing. Trans $R$ Soc Trop Med Hyg 1982;76: 1648.

12 Serva V, Karim H, Ebrahim GJ. Breast feeding and the urban poor in developing countries. $f$ Trop Pediatr 1986;32:127-9.

\section{A little space in Sheffield}

Life sciences research in space is still in its infancy despite solving the initial problems of keeping humans alive in such an inhospitable environment. To the earthbound clinician such endeavours have had little professional impact, although there are promises of greater understanding of cardiovascular, respiratory, and vestibular physiology, mineral metabolism, and locomotion. The prospect of such research has encouraged the University of Sheffield to set up the United Kingdom's first institute for space biomedicine, which was inaugurated on 19 October.

The institute's funding is limited at present to a two year grant totalling $£ 50000$ from the university. The announcement about finances produced some surprise at the launch press conference, but the director of the institute, Professor Tim Scratcherd, confirmed that "We're currently thinking in terms of $£ 10^{3}$ rather than $£ 10^{9}$." Scratcherd would welcome government funding and he had been optimistic after initial positive discussions with the British National Space Centre. The rest of the story is history: Roy Gibson, the director of the centre, resigned from his post on 30 September owing to the government's decision not to increase its annual contribution to the European Space Agency's budget. So not surprisingly the timing of the institute's launch provided a forum for considerable discussion on government funding of space research in general.

Sir Geoffrey Pattie, ex-information technology minister, who opened the institute's launch symposium, declared that a "fog of myopia had fallen on the government" on the subject of investment in space. As a world trader and producer Britain could not afford to opt out of this field, yet our spending was "virtually in the noise level." Further evidence of the United Kingdom's lack of commitment to space research, especially in the biosciences, was presented by Dr Heinz Oser, director of life sciences of the European Space Agency. The United Kingdom's contribution to the agency's microgravity programme was about $2 \%$ of the total, although smaller countries such as Belgium and Switzerland had each paid over $4 \%$. The bulk of the finance came from Germany (35\%), Italy (18\%), and France (15\%).

Given this impoverished background how can Sheffield possibly succeed in contributing appreciably to space biomedicine? Much will depend on whether the institute will be offered a free flight to put an animal "test bed" into orbit. There were strong hints that the likely benefactor would be the Soviet Union, which would offer a mission in the late 1980 s or early 1990 s. This will presumably employ the Soviet reusable biosatellites, which were later described at the symposium by Academician Oleg Gazenko, head of the Institute for Biomedical Problems, Moscow. With a weight of about five tons, the craft provides about three cubic metres of useful space for automated studies on the animals restrained within it. In the 1990s a larger capsule is planned, probably three times the present size, which could dock with manned space craft and allow humans to work directly with the animal studies.

If a flight is given to the institute the likely priority for investigation will be the demineralisation of bone that occurs with prolonged space flight. The rapidity with which this occurs in space makes it a useful potential model for predicting the mechanisms concerned in terrestrial osteoporosis. During its investigations the institute would make use of skills and resources from the nine departments at Sheffield with which it has links and, in particular, the department of human metabolism and clinical biochemistry.

Inevitably the institute's autonomy will suffer if its major research expenses are to be met by a third party. I hope that it will have the opportunity to develop into more than just a service laboratory for the Soviets.

F JOHN MILLS

Medical Director,

Janssen Pharmaceutical Ltd,

Wantage,

Oxon OX12 ODQ

\section{Degenerative ataxic disorders: still perplexing}

Degenerative disorders of the nervous system, including dementias, motor system disorders, and the spinocerebellar degenerations, are presenting a bigger problem as the population ages. The disorders result from selective and symmetrical degeneration of one or more groups of neurones. Some are wholly genetically determined, but most are not; often the disease develops because of a combination of genetic and environmental factors. The cerebellar and spinocerebellar degenerations comprise a complex group of over 50 distinct diseases. Their classification is controversial, but in practice they are best subdivided according to clinical and genetic features ${ }^{12}$ rather than pathological criteria. ${ }^{3}$

Degenerative ataxias with recognisable metabolic defects are rare, but their diagnosis is important for genetic counselling and treatment. Some storage diseases more commonly associated with neurodegenerative disorders of childhood, such as hexosaminidase deficiency and the leucodystrophies, 